\title{
The cessation of rising employment rates at older ages in Australia, 2000-2019
}

Peter McDonald* The University of Melbourne and The Australian National University Helen Moyle The University of Melbourne

* Corresponding author. Email: mcdonald.p@unimelb.edu.au. Address: Melbourne School of Population and Global Health, University of Melbourne, 207 Bouverie St, Vic 3010, Australia.

Paper received 28 January 2020; accepted 1 May 2020; published 25 May 2020.

\begin{abstract}
Background

In the first decade of the 21st century, employment at older ages surged in Australia, benefitting the Australian economy. Subsequent to 2010, however, employment rates at older ages ceased rising for older men and the increases were much more moderate for women.
\end{abstract}

Aim

The aim of this paper is to examine these older-age employment trends in more detail, particularly the association between older-age employment trends and the business cycle. Some attention is also given to alternative explanations related to changes in the characteristics of the population and industrial structure.

\section{Data and methods}

Two main data sources are used: published tables from the monthly Australian Bureau of Statistics Labour Force Surveys and the Australian censuses for the years 2006, 2011 and 2016. The methods used are primarily descriptive.

\section{Results}

Strong labour demand in the first decade of the 21st century stimulated the entry to employment of those out of the labour force, especially at ages 45-54 and especially for men. A cooling of labour demand following the global financial crisis terminated this process in the second decade. There were strong associations between older age employment and various socio-economic characteristics, but, in general, changes in the composition of the population or in the rates of employment by these characteristics did not contribute to the cessation of rising employment after 2010.

\section{Conclusions}

Employment rates at older ages in Australia in the first two decades of the 21st century were the results of shifts in labour demand before and after the global financial crisis. Policy related to the taxation of superannuation also induced workers with adequate superannuation, especially public sector workers, to continue working to at least age 60.

\section{Key words}

Older age employment, Australia, labour demand, superannuation, gender differences. 


\section{Introduction}

The first Intergenerational Report (Department of the Treasury 2002) promoted the benefits of an increase in employment at older ages because it would mean that people would be on the tax-paying side of the ledger rather than on the tax-disbursal side. Working longer would also mean that the people concerned would be able to build up their superannuation entitlements before retiring, again reducing the government's potential future liability. Subsequent official reports made the same arguments (Productivity Commission 2005; House of Representatives Standing Committee on Health and Ageing 2005). As a result, several policy initiatives were introduced to encourage older age employment (Productivity Commission 2005, Swoboda 2014). The 2010 Intergenerational Report (Department of the Treasury 2010) raised the additional concern that economic growth would be under significant pressure as the baby-boom generation retired from the labour force. This effect is clearly demonstrated by economic modelling (Bloom et al. 2011; Temple and McDonald 2017).

In the first decade of the 21st century, employment at older ages surged in Australia (McDonald 2011) and it has been demonstrated that this surge of older age employment benefitted the Australian economy as had been predicted (Temple et al. 2017). Subsequent to 2010, however, employment rates at older ages ceased rising for men and the increases were much more moderate for women (see Section 3). The aim of this paper is to examine older-age employment trends in Australia over the 20002019 period, and in particular the association between older-age employment and the business cycle.

\section{ABS labour force definitions}

The analysis focuses upon 'employment' rather than 'unemployment' or 'labour force participation'. This is because the distinction between unemployment (not employed but actively looked for work at some time in the past four weeks and available for work in the week preceding the survey) and not being in the labour force (not employed or unemployed) can be somewhat arbitrary at older ages. This is especially the case because 'looked for work' does not include scanning job advertisements in the newspaper or the internet. Persons in employment are defined as those aged 15 years and over who, during the week preceding the data collection, were engaged for at least one hour in any activity to produce goods or provide services for pay or profit, or were temporarily absent from work so defined (ABS 2018a).

By these definitions a person very actively engaged in voluntary work (not for pay or profit) is not considered to be employed. Criticisms are sometimes made of the low, one-hour criterion to qualify as 'employed' but this is a very minor issue because, in Australia, less than five percent of employed persons are employed for under 10 hours per week (ABS 2019a).

While these definitions are consistent across Australian Bureau of Statistics data collections, the ABS advises that the definitions are not as tightly applied in the Australian censuses as they are in the Labour Force Surveys, the two sources used in this paper. However, as shown in the next section, the same old-age employment trends are evident from both sources. 


\section{Older-age employment trends, 2000-2019}

Monthly employment rates from January 2000 to November 2019 from the ABS Labour Force Survey are shown for men and women aged 55-59, 60-64 and 65+ in Figure 1. Changes in employment rates for the age group 65+ may be misleading if the age structure within the age group 65+ shifts to the younger or older ends of this range. However, scrutiny of age structure changes in Australia indicates that this was not an issue for the period under consideration here.

For men in all three age groups, the employment rate peaked around the end of 2010 and then flattened. For those aged 60-64 and 65+, the levels seem to have risen a little in 2018 and 2019. Rates for men aged 55-59, however, appear to have fallen a little since 2010. The very recent increases in employment in the two older age groups for men may have been affected by the increase in the pension eligibility age from 65 to 67 years between July 2017 and July 2023. For women aged 55-59 and 60-64, the rises in employment were even stronger than those for males in the first decade and, after levelling off for a few years immediately after the crisis in late 2008 and early 2009, women's rates of employment continued to rise from around 2014 onwards albeit at a slower pace than before the crisis.

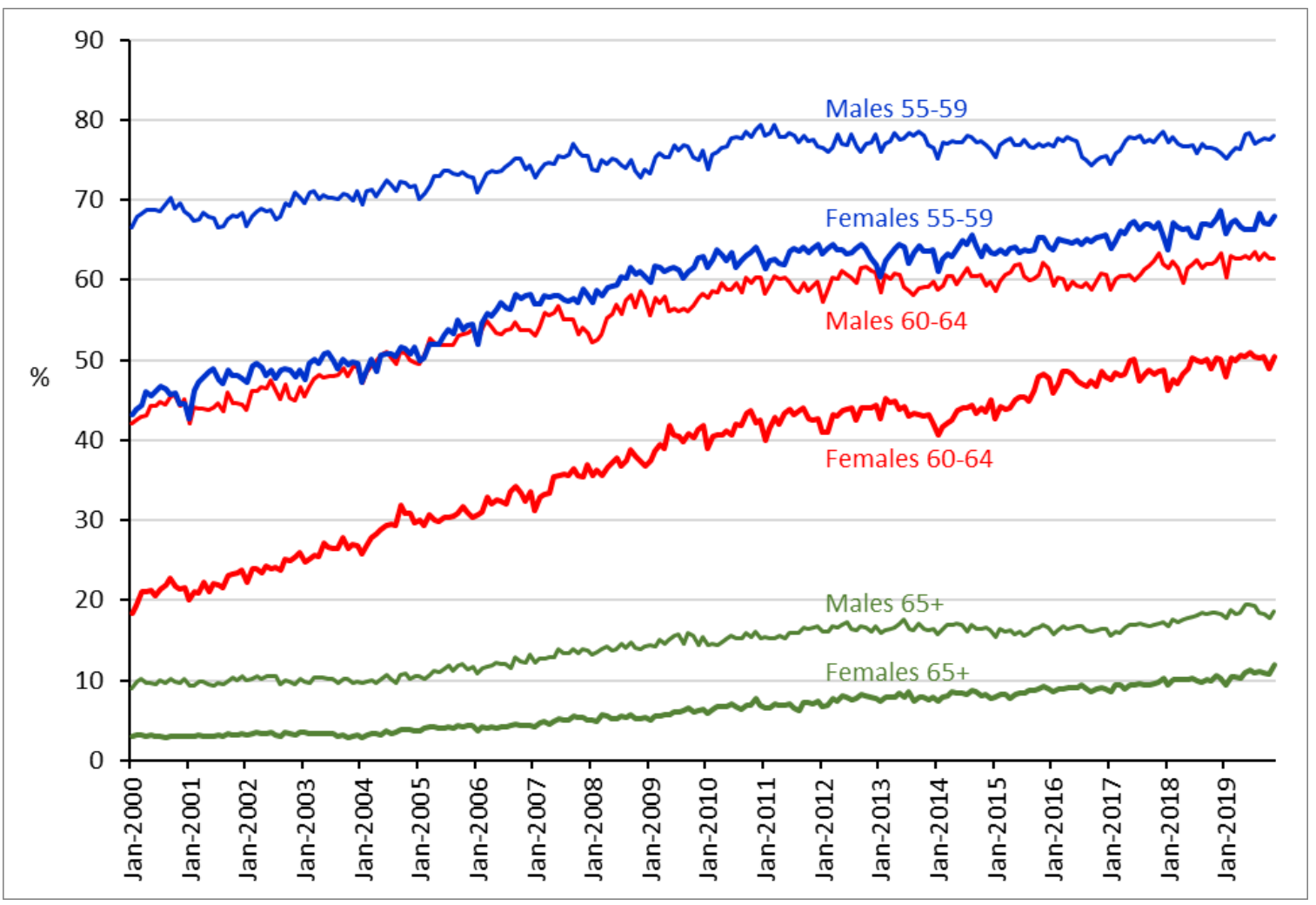

Figure 1: Percentage employed by sex, age groups 55-59, 60-64 and 65+, Australia, January 2000 to November 2019

Source: ABS 2019a

Figure 2 shows that the increases in older-age employment in the first decade were very likely to have been influenced by earlier rises in employment at younger ages. Employment participation at ages 45-49 and 50-54 rose strongly from around 1998 through to the time of the global financial 
crisis. Subsequently, participation at these ages fell for both men and women, with rises for women only from 2014 onwards.

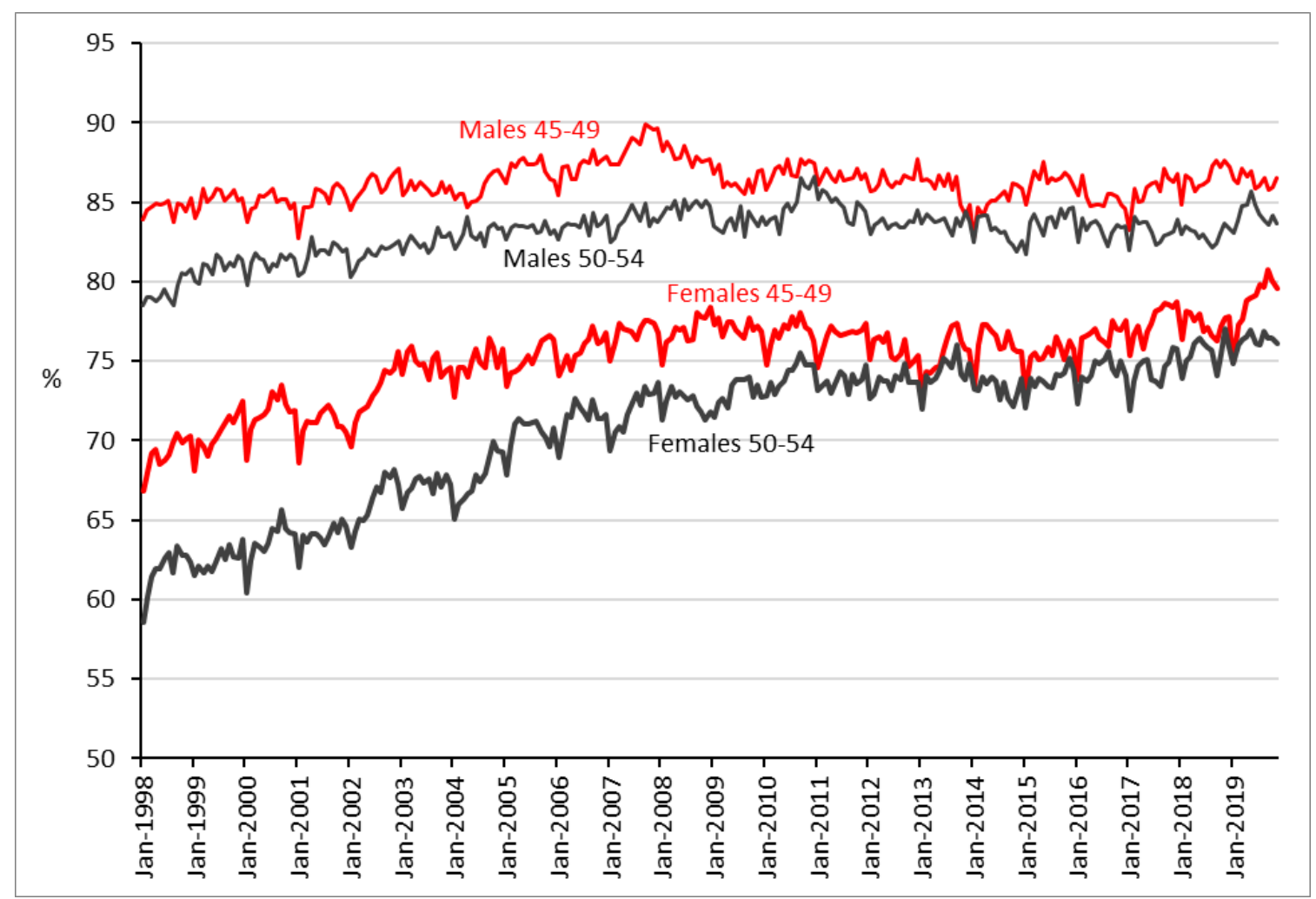

Figure 2: Percentage employed by sex, age groups 45-49 and 50-54, Australia January 1998 to November 2019

Source: ABS 2019a

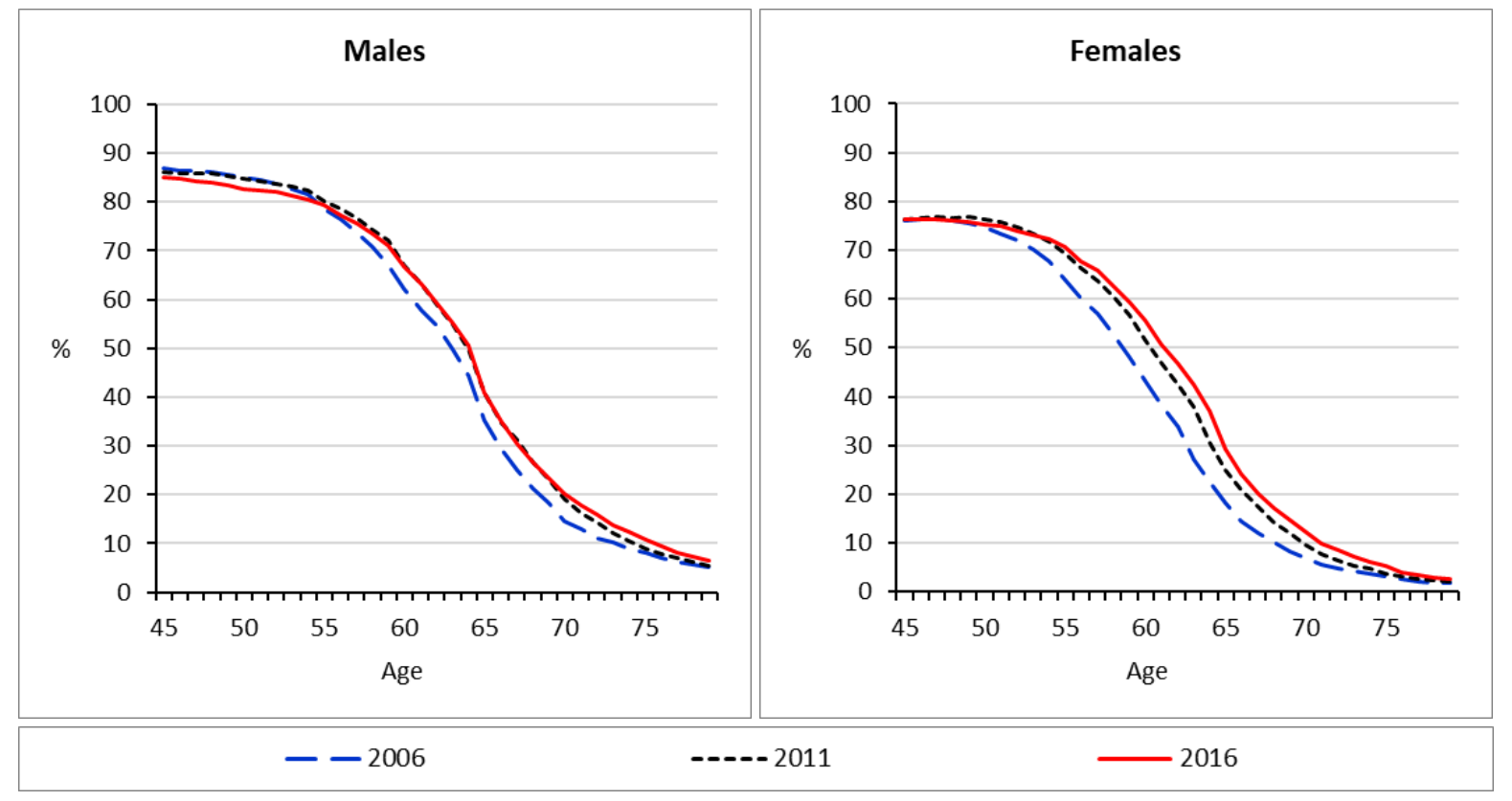

Figure 3: Percentage employed by single years of age, ages 45-79, Australian censuses, 2006, 2011 and 2016 Source: ABS 2016 
Using census data (Figure 3), it is possible to examine trends across time by single years of age. Importantly for subsequent analysis, this figure indicates a strong degree of consistency between the trends in the Labour Force Surveys and the censuses. In addition, it shows that for both men and women, the rate of employment tends to drop monotonically with age from age 50 onwards without much acceleration around the pension eligibility ages or any other age.

A potential argument is that the trends in older-age employment rates may have been the result of changes in labour supply at these ages: that supply was constrained in the first decade but increased strongly in the second decade. Counter to this argument, however, Table 1 shows that, for age groups 55-59 and 60-64, the rates of population growth were much higher in the first decade than in the second decade. The reverse was the case for the 65 and over age group. For those aged 55-64, employment levelled off in the second decade even though the population of potential workers was growing more slowly than in the first decade.

Table 1: Rates of population growth for older age groups, persons, 2001-10 and 2010-19

\begin{tabular}{lcc}
\hline Age Group & $\begin{array}{c}\text { Annual rate of population growth (\%) } \\
\text { 2001-09 }\end{array}$ & $\mathbf{2 0 1 0 - 1 9}$ \\
\hline $55-59$ & 3.0 & 1.8 \\
$60-64$ & 4.2 & 1.7 \\
$65+$ & 2.3 & 3.4 \\
\hline
\end{tabular}

Source: ABS 2019a

In relation to the hours of work for those employed, Table 2 shows that, as expected, women were much more likely to work part-time than men in all three older age groups. However, across time, there were small increases in the percentage of men working part-time and small decreases in parttime employment among women, in all age groups. The long-term rise (from the 1990s) in the pension eligibility age for women from 60 to 66 may have had a bearing on the rises in employment, particularly for women aged 60 and over.

Table 2: Percentage of employed persons working part-time, males and females, age groups 55-59, 60-64 and 65+, June 2000 and June 2019

\begin{tabular}{llcc}
\hline Sex & Age group & June 2000 & June 2019 \\
\hline \multirow{4}{*}{ Males } & $55-59$ & 11.9 & $\%$ \\
& $60-64$ & 18.6 & 13.2 \\
& $65+$ & 42.6 & 23.5 \\
Females & $55-59$ & 49.8 & 48.4 \\
& $60-64$ & 56.2 & 44.0 \\
& $65-+$ & 70.1 & 54.0 \\
& & & 64.6 \\
\hline
\end{tabular}

Source: ABS 2019a

The downward trend in both employment and full-time employment for men aged 55-59 is very unlikely to have been due to incentives to retire early because these ages are well below the pension eligibility age and below the age at which superannuation can be withdrawn tax-free (60 years). Thus, this trend suggests involuntary causes. 


\section{Retention analysis}

From the ABS Labour Force Surveys, it is possible to examine the net probability of retention in employment for cohorts as they age from 55-59 years in one survey to 60-64 years in the survey five years later. Figure 4 shows these retention rates averaged for the months of June and July. Averaging was applied to reduce the effects of sampling variation, but the rates for individual months show very similar trends. While this is a 'net' probability with new entries balanced off against exits, longitudinal analysis from the censuses presented below indicates that entries to employment at these ages are uncommon.

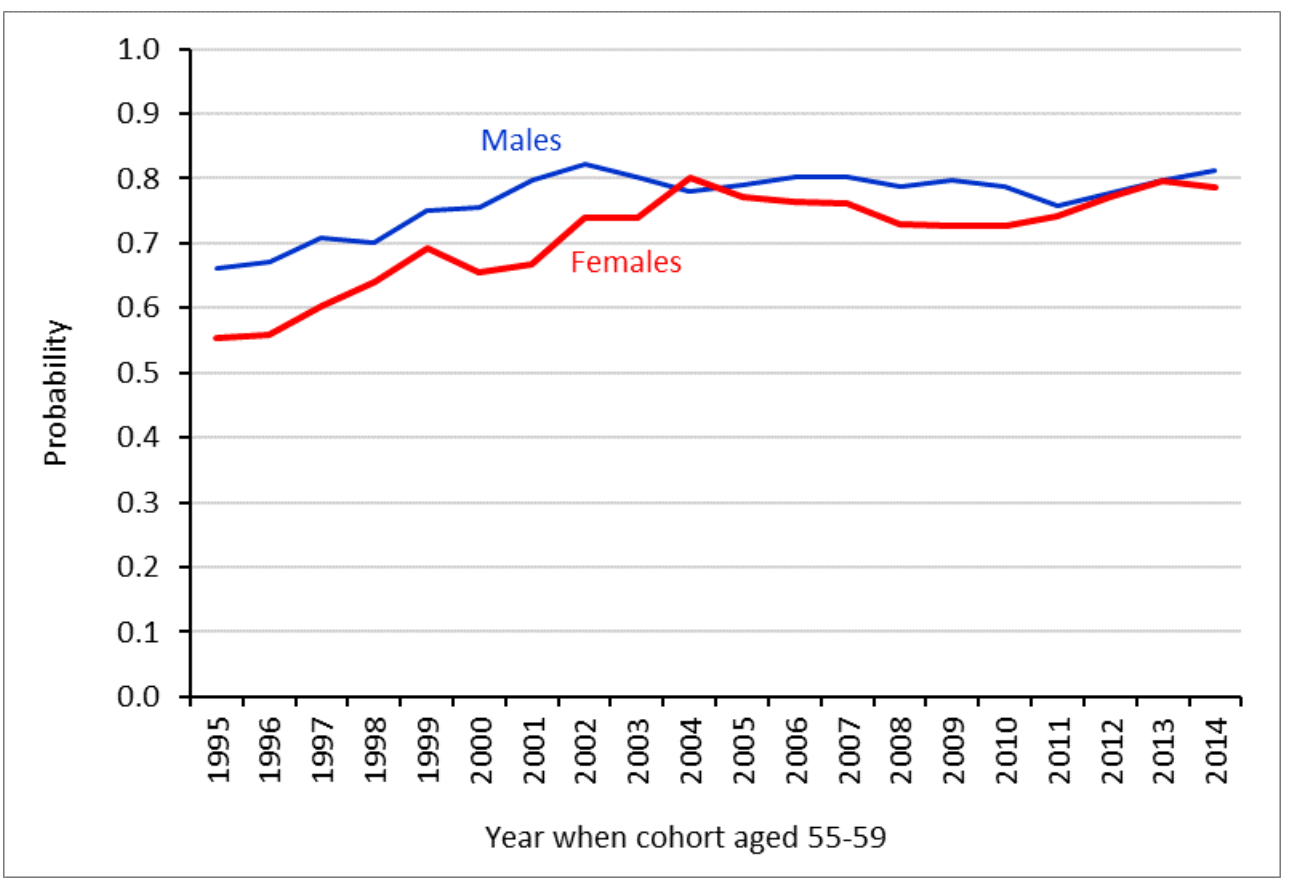

Figure 4: Net cohort probability of employment retention, age group 55-59 to age group $60-64$, by year aged 55-59, average of months of June and July

Source: Derived from ABS 2019a

The interesting feature of this chart is that the probability of retention for both men and women levelled off from as early as the 2002 to 2007 period for men and 2004 to 2009 for women, earlier than the point at which the employment rates flattened (around 2010). This means that the flattening of employment rates for age group 60-64 was the result of the cessation of increases of employment rates in age group 55-59, rather than a drop in the retention rate between 55-59 and 60-64.

Similar data are shown by single years of age and for a wider range of ages for the two intercensal periods, 2006-11 and 2011-16 in Figure 5. The more refined, single year of age data show some effect of the pension eligibility ages, particularly for men. Interestingly, the charts for both men and women indicate that retention rates level off from age 65 onwards (retention from 60 to 65 in the chart) at about 50-60 per cent, although, at these ages, retention fell somewhat from the first to the second intercensal period. For men, the retention rates were lower in the 2011-16 period than in the 200611 period from age 55 upwards. Thus, to a small extent, lower retention across time, especially for men, was a contributing factor to the flattening of employment rates. 


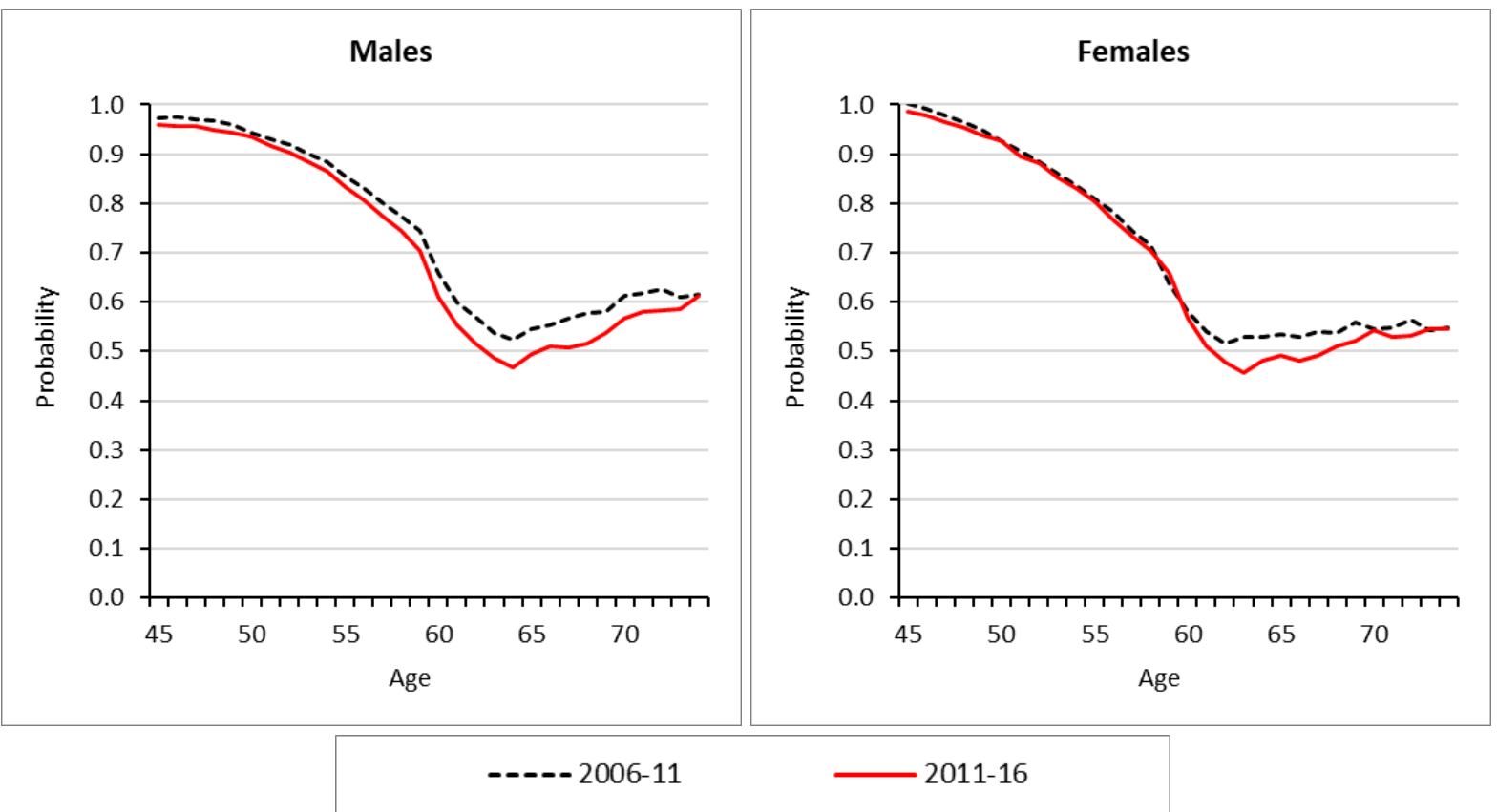

Figure 5: Net cohort probability of retention in employment across five-year intercensal periods by age at the start of the intercensal interval

Source: Derived from ABS 2016

\section{Leaving and entering employment at older ages}

The longitudinal census databases enable the tracking of the employment of individuals across intercensal periods. Rather than 'net' retention as applied in the previous section, the separate components of exit and entry can be examined from these data. The percentages leaving employment by age were quite similar across the two intercensal periods for both men and women but a little higher at older ages for the 2011-16 period compared with the 2006-11 period (Figure 6A). The life table data (Figure 6B) provide a perspective on the cumulative impact of the different rates of entering employment across the two intercensal periods; the impact is almost negligible.

The rates of entering employment are noticeably higher at the younger ages for the 2006-11 period compared with the 2011-16 period (Figure 7A) and these rates convert into higher cumulative rates of entry based on the life table data (Figure 7B). Indeed, most of the life table effect of entry to employment is achieved by the mid-50s ages.

The conclusion to be drawn from this analysis of leaving and entering employment is that employment rates at older ages increased before 2010 not because of higher employment retention but because of high rates of entry among those who were not employed. The rates then flattened after 2010 because the rates of entry for those not employed were lower in the later period. Also, the higher rates of entry to employment in the first period had their main effect at younger ages (late 40 s and early 50s). These results support the hypothesis that the growth of employment at older ages was the result of strong labour demand prior to 2010 which dissipated after 2010. From a policy perspective these results imply that, if the aim is to increase older age employment, there should be a focus on increasing employment participation below age 55 . Higher rates would then persist into older ages because of the relative constancy of retention rates. To confirm this hypothesis, individual 
level statistical analysis could examine whether people who entered employment during the economic boom in middle age continued to be employed into the future.
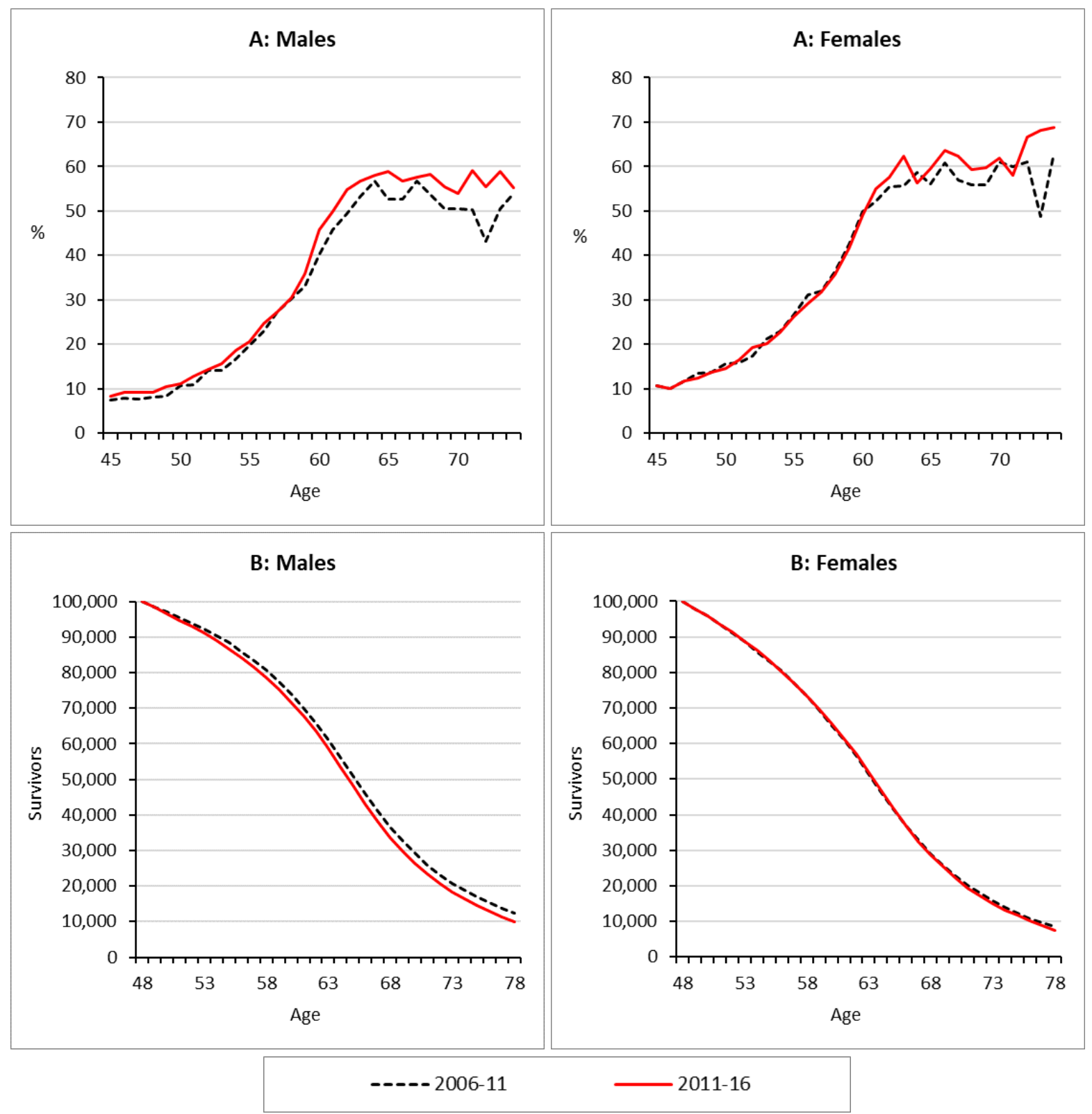

Figure 6: A. Percentage leaving employment between censuses by single years of age, 2006-11 and 201116 ; $B$ : The same data in a cumulative life table format Source: ABS 2018b

Notes: A: This is the rate (\%) at which employed persons by their age at the first census are not employed five years later at the succeeding census. B: From an initial cohort of 100,000 employed persons at exact age 48 , B shows the number still employed at subsequent exact ages when subjected cumulatively to the rates shown in $A$. 

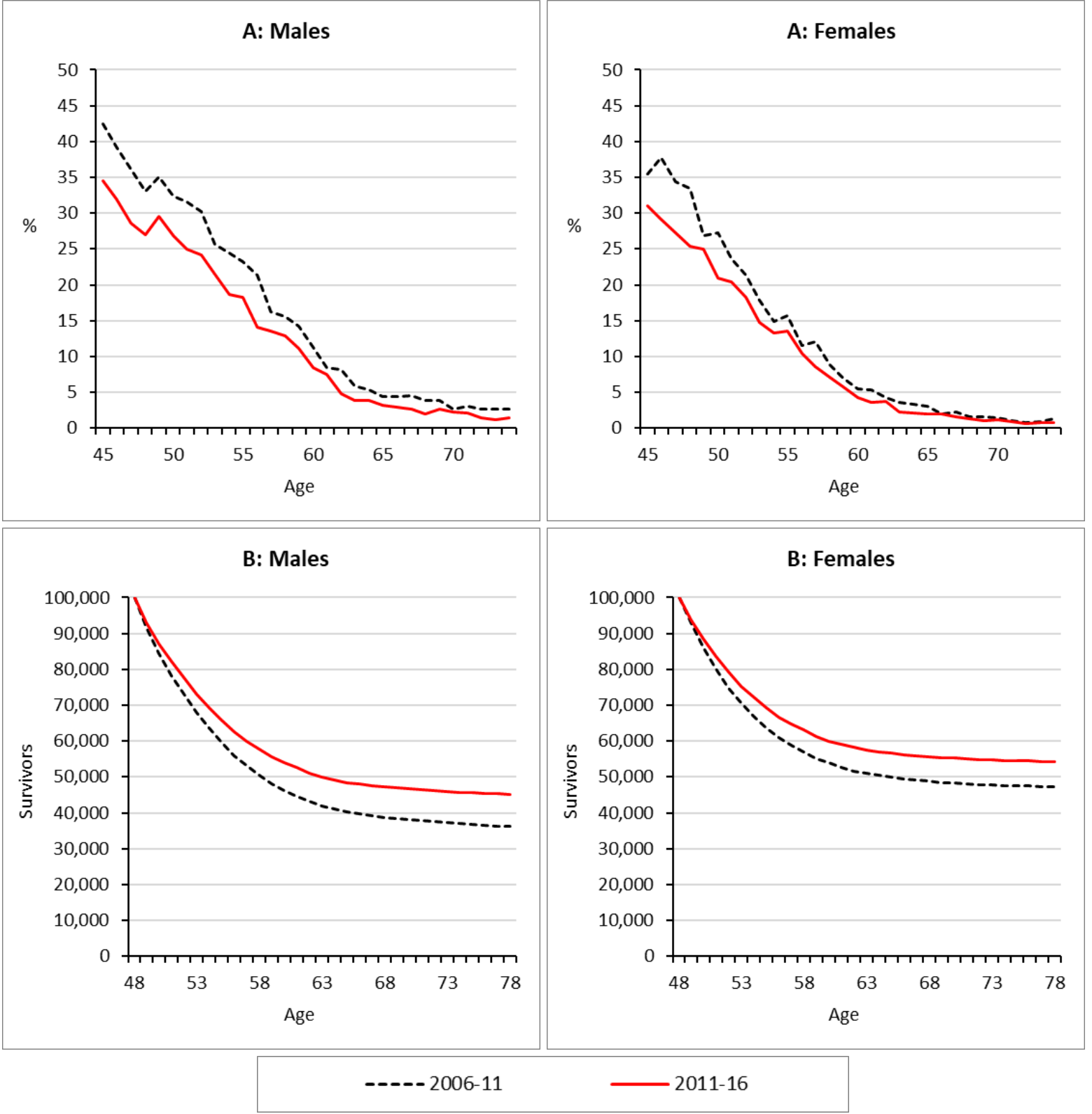

Figure 7: A. Percentage entering employment between censuses by single years of age, 2006-11 and 201116; B: The same data in a cumulative life table format

Source: ABS 2018b

Notes: A: This is the rate (\%) at which persons not employed by their age at the first census are employed five years later at the succeeding census. B: From an initial cohort of 100,000 not employed persons at exact age 48 , B shows the number still not employed at subsequent exact ages when subjected cumulatively to the rates shown in $A$.

\section{Reasons not employed}

The ABS monthly Labour Force Surveys include a question on reasons for not being in the labour force. In Figure 8, these responses for persons aged 55-64 are combined with those persons reported to be employed and unemployed. The result shown in Figure 8 is a distribution from April 2001 to November 2019 of all persons into four categories: employed, unemployed (formal) plus others who looked for work in any way, those who did not look for work, and those institutionalised or permanently unable to work. 

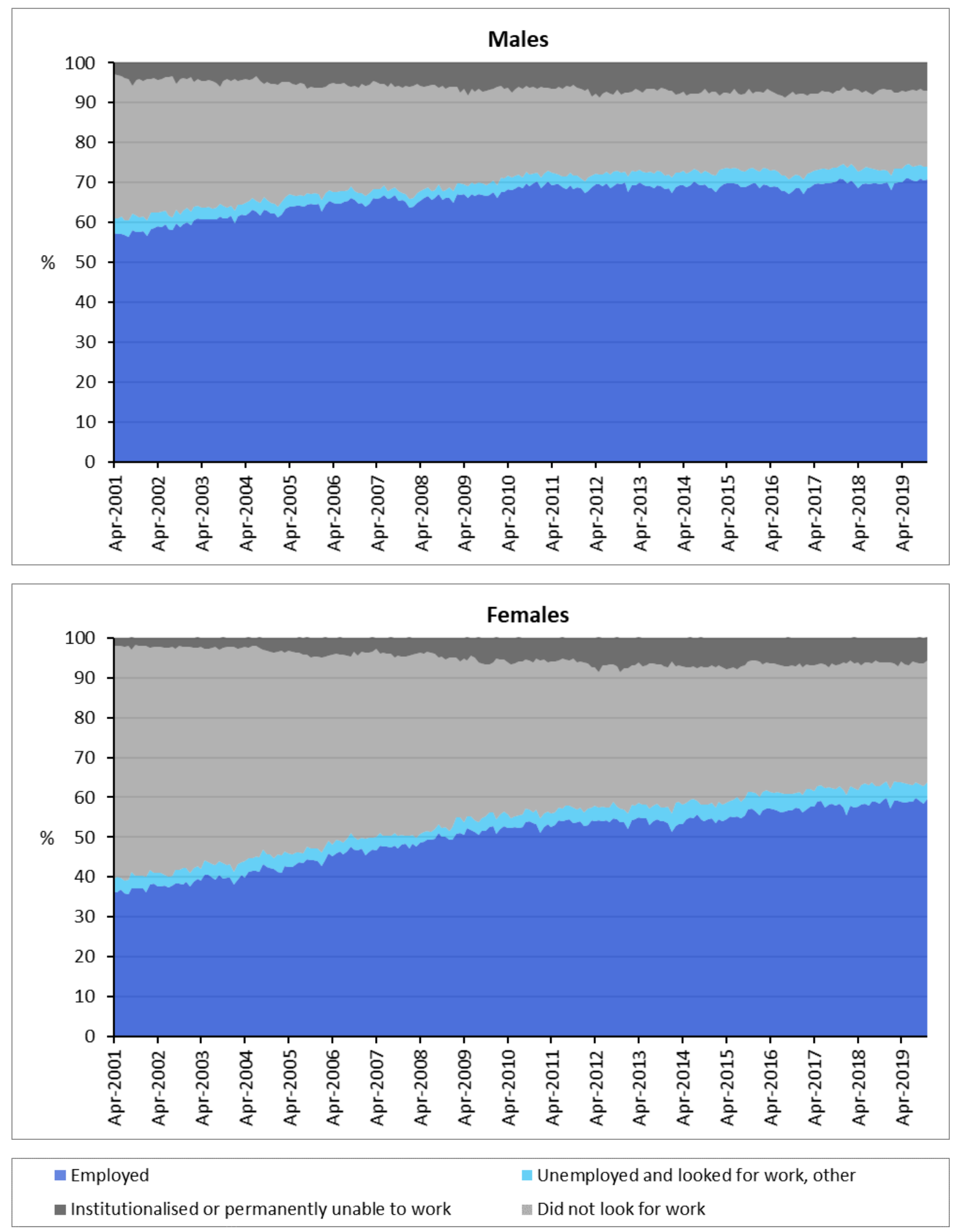

Figure 8: Percentage employed and reasons for not being employed, persons aged 55-64, Australia, April 2001 to November 2019

Source: ABS 2019b 
The figures for both men and women show that change from 2001 to 2010 was related to a shift out of the category 'did not look for work' into the two categories, 'employed' and 'institutionalised and permanently unable to work'. From 2010 onwards, there is almost no change, especially for men. There was little change in the 'unemployed or looking for work' category.

The strong labour demand from 2001 to 2010 appears to have led many in the 'did not look for work' category into employment - and this may have occurred at ages earlier than 55 . Others from the same category in the same period shifted into 'institutionalised or permanently unable to work'. The percentages institutionalised were stable across time, so this was a result of people reporting themselves as 'permanently unable to work' - presumably persons receiving the Disability Support Pension which increased in value substantially during this period compared with the benefit paid to those unemployed. Once more, a policy of promoting employment among discouraged job seekers aged 45 and over, particularly 45-54, seems appropriate especially if labour demand is strong.

\section{Occupational change}

Having concluded that older-age employment increased in the first decade of the 21st century because of higher rates of employment at younger ages (45-54) from about 1998 onwards combined with retention of those workers across time, it is useful to consider this in terms of occupations. Figure 9 shows two groupings of occupation for men and women that account for around 75 per cent of all workers around age 55. The two groups can be classified as higher (Managers and Professionals for both men and women) and lower (Technicians, Trades, Machine Operators and Drivers for men; Clerical, Administrative and Community and Personal Services Workers for women).

The first point to make is that leaving employment around the pension age is much more prevalent for the lower occupations than for the higher occupations. For men, these are 'manual' jobs that may become more difficult to perform with increasing age. Interestingly, however, the occupation of labourer, the most physically demanding occupation, maintained its percentage of total male and female employment with increasing age (not shown). For women, leaving employment is more frequent around the pension age for those in the lower, white collar group. Given that men with higher level occupations are more likely to be married to women with higher level occupations, joint decision making may have a role in these patterns.

More importantly for the theme of this paper, across time the lower level occupations for both men and women make up a larger proportion of employment at the oldest ages (63-73). This strongly suggests, as might be expected, that those who entered employment at younger ages from 1998 (during the boom years) and subsequently retained employment primarily entered the lower level occupations.

\section{Other employment differentials}

It has been demonstrated with earlier data that there are some significant differences in employment status at older ages by socio-economic characteristics (McDonald 2011). There is a potential that employment rates flattened at older ages after 2010 because of changes in the 

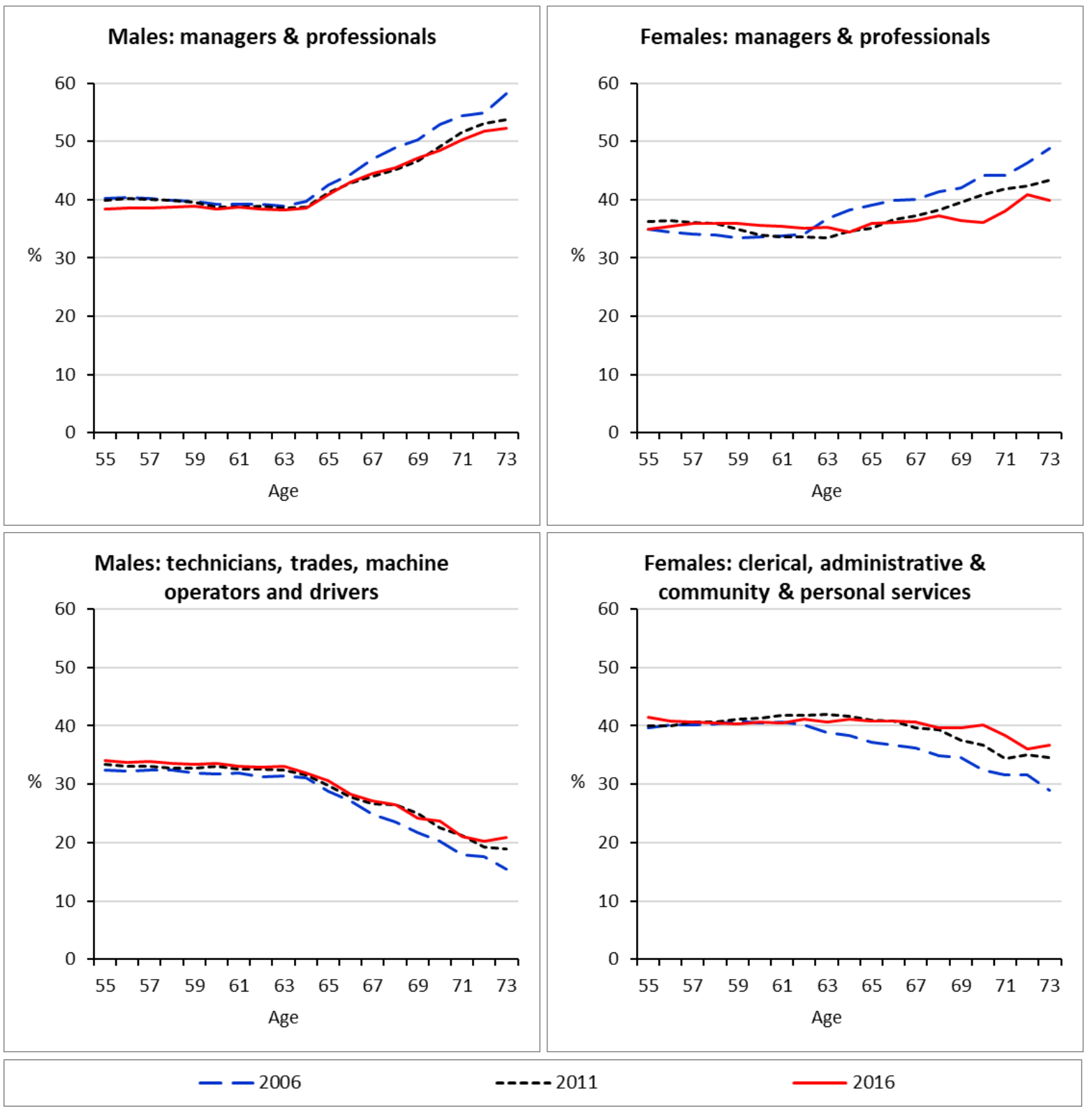

Figure 9: Percentage of total employment working in selected major occupation groups by age and sex, 2006, 2011 and 2016

Source: Derived from ABS 2016

structure of the older age population by characteristics associated with employment. To consider this possibility, this section briefly examines more recent data on the socio-economic determinants of employment at older ages.

Earlier withdrawal from employment is heavily associated with being an employee rather than being an employer or self-employed for both men and women (Figure 10). However, the changes across time are small and are unlikely to have contributed to the flattening of participation at older ages after 2010.

Public sector employment as a percentage of total employment falls off very sharply at older ages for both men and women (Figure 11). Public sector employees normally have good superannuation and the time trend data suggest that superannuation policy changes commencing on 1st July 2007 which 


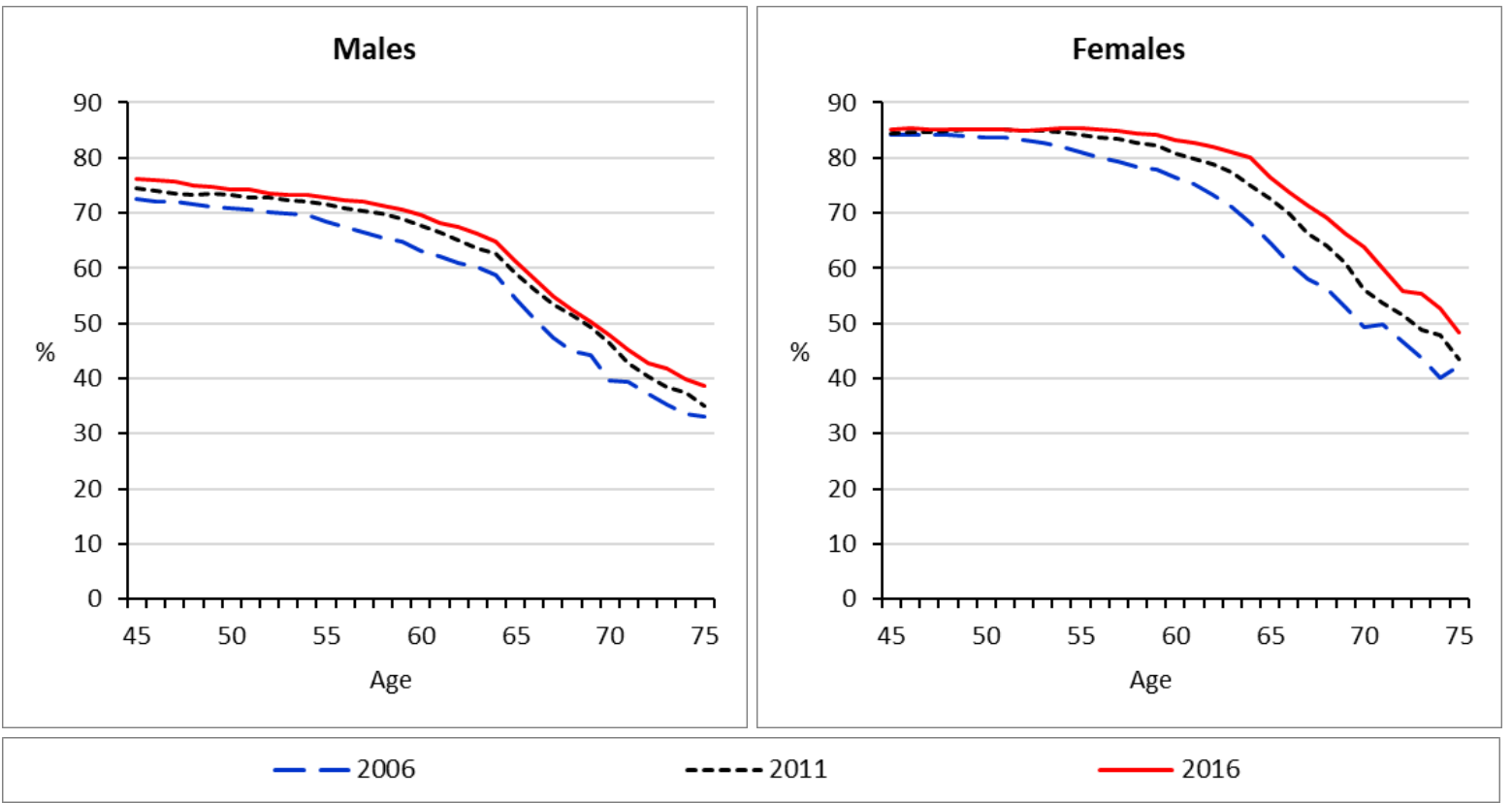

Figure 10: Employees as a percentage of total employment by age and sex, 2006, 2011, and 2016 Source: Derived from ABS 2016

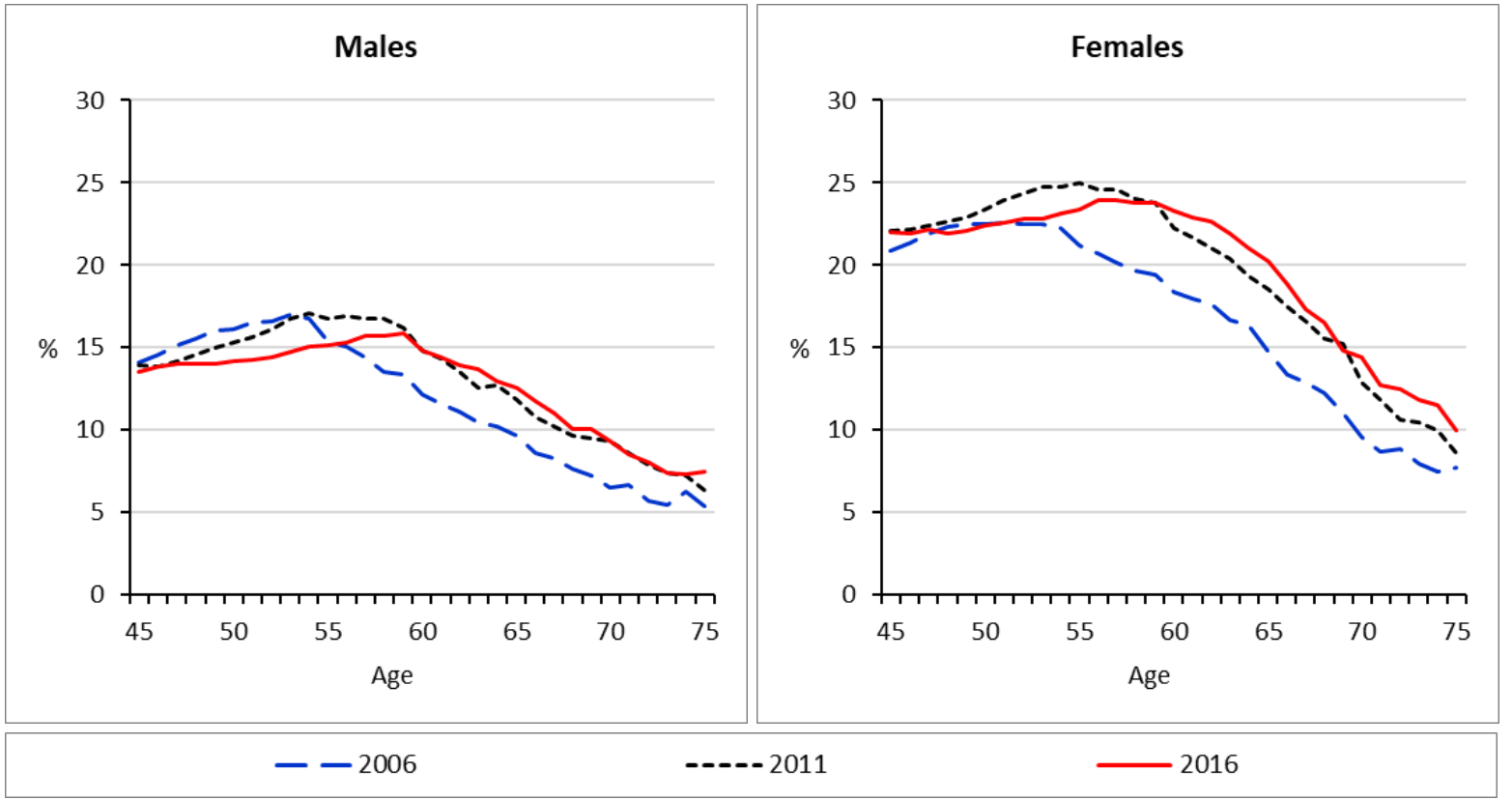

Figure 11: Public sector employees as a percentage of total employment by single years of age and sex, 2006, 2011 and 2016

Source: Derived from ABS 2016

provided major superannuation incentives to continue working to age 60 had a large impact on the retention of public sector workers. The chart clearly shows that employment for public sector workers fell off from age 55 in 2006 but this shifted to 60 from 2011 onwards. As public sector employment is a much higher percentage of total employment for women than for men, this would have contributed to better employment participation outcomes for women overall in the post-2010 period. This analysis suggests that public sector employees stop working in the public sector because of a positive retirement income effect. 

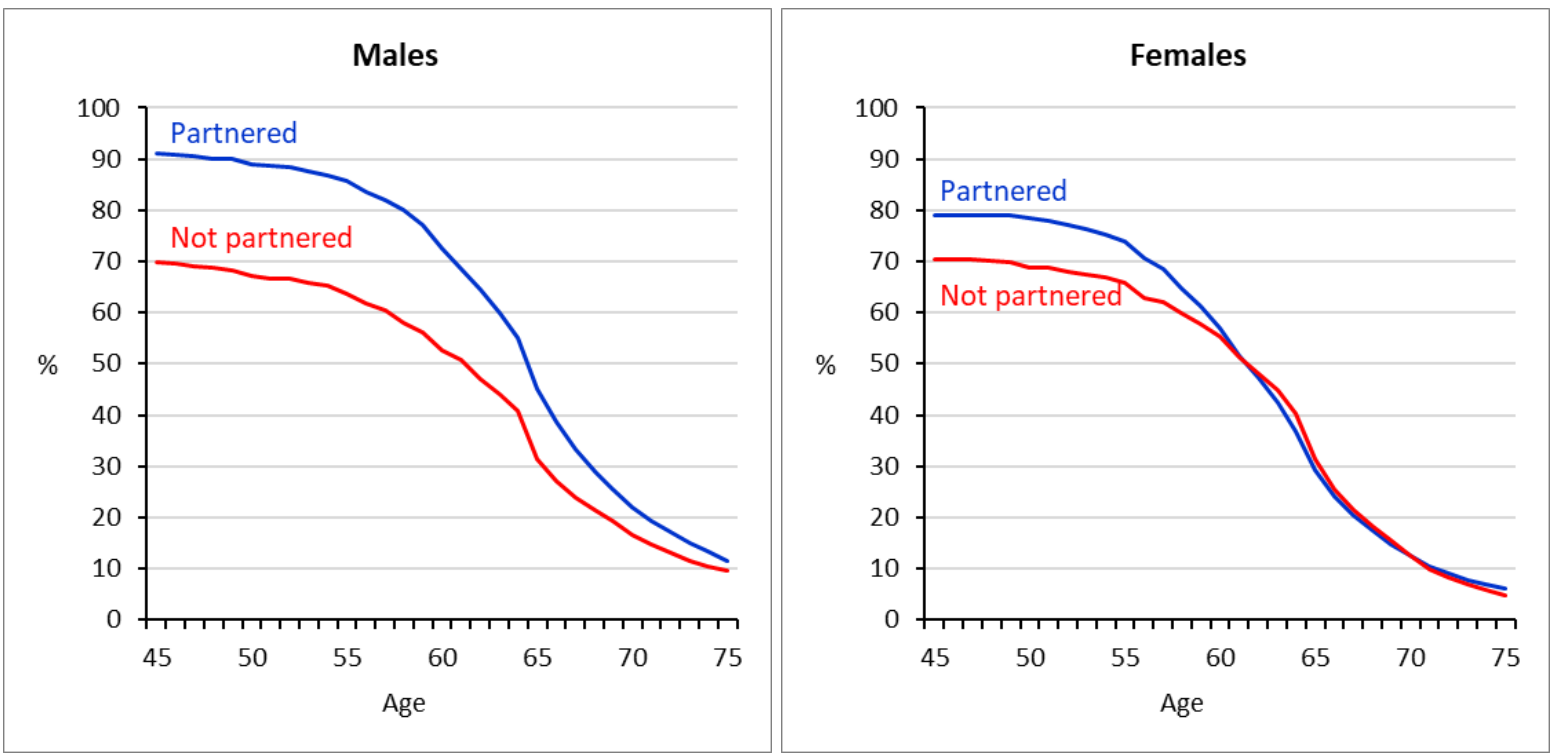

Figure 12: Percentage employed by partner status, sex and age, 2016

Source: Derived from ABS 2016

For both older men and women, being partnered has a strong positive association with being employed (Figure 12). For those not partnered, employment rates for men and women are the same at all ages. While these differences are interesting, the same patterns are observable over time and disaggregation by partner status does not contribute to an explanation of the flattening of employment rates at ages 55 and over after 2010. However, employment rates for not partnered men between ages 45 and 54 were much lower in 2016 than they had been in 2006 and 2011 (not shown). In addition, the proportion of men at older ages who are not partnered is increasing over time. This will provide a small impetus towards lower employment for men aged 55-59 in the immediate future.

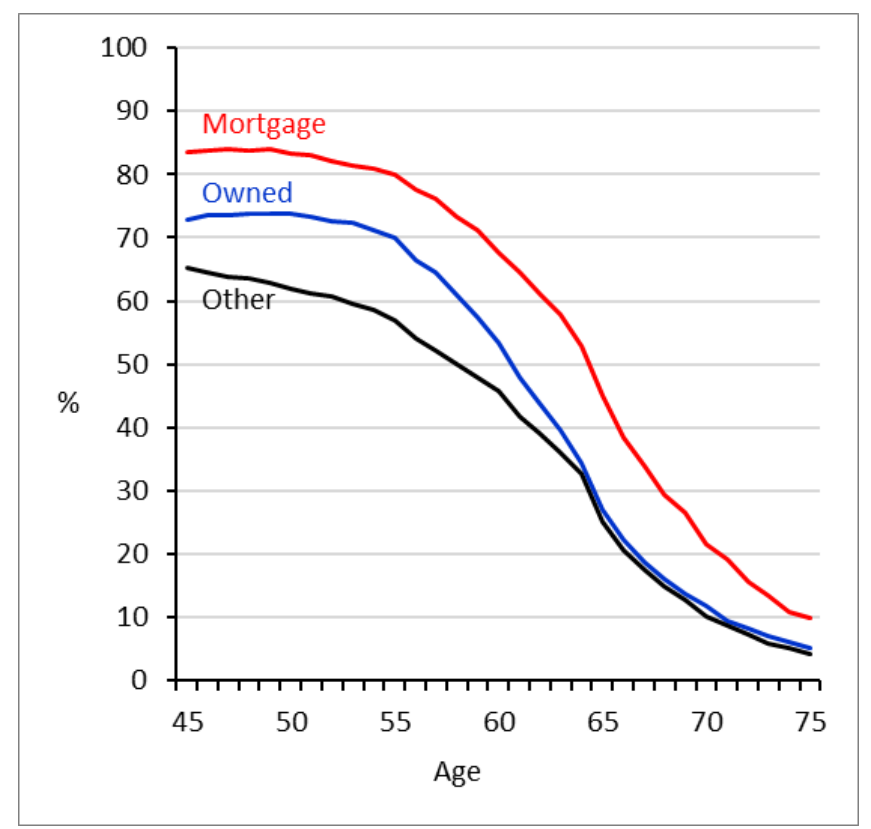

Figure 13: Percentage employed by housing tenure, males by age, 2016

Source: Derived from ABS 2016 
Previous research based on 2006 Census data has shown that, at older ages, persons holding a mortgage are more likely to be employed than full owners or renters (McDonald 2011). These differences were still evident in 2016 (Figure 13). However, within each tenure category, there was very little change in employment participation from 2006 to 2016 at older ages and, where there was change, it was consistent with the pattern for all men (not shown). However, the proportions of men holding a mortgage at older ages is increasing a little across time which could have a small positive impact on employment at older ages in the future.

\section{Conclusion}

The central conclusion of the analysis is that, for both men and women, older age employment increased in the first decade of the 21st century because expanding labour demand from 1998 drew people into employment who were not in the labour force, especially at ages $45-54$. Once in employment, those recruited in this way appear to have remained in employment. Entry rates rose while retention rates remained stable. This pattern was more evident for those who entered lowerlevel occupations. This suggests that people out of the labour force who gain employment gather self-confidence and work experience that enables them to continue in employment. When labour demand cooled after the global financial crisis, entry rates stopped rising and, consequently, employment participation at older ages levelled off.

Specific to those with adequate superannuation, especially public sector workers, the analysis suggests that the 2007 policy changes to the taxation of superannuation induced more people to continue working until at least age 60 . As the coverage of adequate superannuation grows, these policies should have a wider effect.

There are substantial socio-economic differences in employment at older ages. Married men are much more likely to be employed than single men; those with a mortgage are much more likely to be employed than full home owners or renters; those in good health are much more likely to be employed that those who are not (Cai and Kalb 2007; Zucchelli et al. 2010); and employees and public sector workers are much more likely to retire earlier than other workers. However, the analysis here suggests that these differences along with structural changes in the characteristics of the population were insufficient to account for very much of the main employment changes at older ages. Accordingly, there is little evidence of any long-term, social trend towards employment at older ages.

\section{Key messages}

- For both men and women, older age employment increased in the first decade of the 21st century because expanding labour demand from 1998 drew people into employment who were not in the labour force, especially at ages 45-54.

- Subsequently, retention rates remained stable. This pattern was more evident for those who entered lower-level occupations.

- The 2007 policy changes to the taxation of superannuation seem to have induced more people to continue working until at least age 60, especially public sector workers. 
- Changing socio-economic characteristics of the population and changes in employment rates associated with those characteristics had only minor impacts on aggregate employment trends.

- There is little evidence of any longer-term social trend to higher employment at older ages.

\section{Acknowledgements}

The paper was prepared as part of the research endeavour of the ARC Centre of Excellence in Population Ageing Research (CEPAR).

\section{References}

ABS (2016) Census of Population and Housing 2006, 2011 and 2016 (accessed via TableBuilder). Canberra ABS. https://www.abs.gov.au/websitedbs/D3310114.nsf/home/About+TableBuilder

ABS (2018a) Labour Statistics: Concepts, Sources and Methods, Feb 2018. Catalogue No. 6102.0.55.001. Canberra: ABS. https://www.abs.gov.au/ausstats/abs@.nsf/mf/6102.0.55.001

ABS (2018b) Australian Census Longitudinal Dataset (ACLD) (accessed via TableBuilder). Canberra: ABS. https://www.abs.gov.au/websitedbs/D3310114.nsf/home/About+TableBuilder

ABS (2019a) Behind the numbers: How many people work one hour/week? ABS Media Release, 14 February 2019.

https://www.abs.gov.au/ausstats/abs@.nsf/Lookup/6291.0.55.001Media\%20Release1Dec\%2020 $\underline{18}$

ABS (2019b) Labour Force Australia, Detailed - Electronic Delivery. Catalogue No. 6291.0.55.001. Table 01 Canberra: ABS.

https://www.abs.gov.au/AUSSTATS/abs@.nsf/DetailsPage/6291.0.55.001Nov\%202019?OpenDoc ument

ABS (2019c) Labour Force Australia, Detailed - Electronic Delivery. Catalogue No. 6291.0.55.001. Table NM1 Canberra: ABS

https://www.abs.gov.au/AUSSTATS/abs@.nsf/DetailsPage/6291.0.55.001Nov\%202019?OpenDoc ument

Bloom D, Canning D, and Fink G (2011) Implications of population ageing for economic growth. NBER Working Paper Series, Working Paper 16705. Cambridge MA: National Bureau of Economic Research.

Cai, L and Kalb, G (2007) Health status and labour force status of older working-age Australian men. Australian Journal of Labour Economics. 10(4): 227-252.

Department of the Treasury (2002) Intergenerational Report 2002-03. 2002-03 Budget Paper No.5. Canberra: Department of the Treasury.

Department of the Treasury (2010) Australia to 2050: Future Challenges (the third Intergenerational report). Canberra: Department of the Treasury.

House of Representatives Standing Committee on Health and Ageing (2005) Future ageing: inquiry into long-term strategies to address the ageing of the Australian population over the next 40 years. Canberra: Parliament of the Commonwealth of Australia.

McDonald P (2011) Employment at older ages in Australia: determinants and trends. In: Griffin T and Beddie F (eds) Older Workers: Research Readings. Adelaide: National Centre for Vocational Education Research, Department of Education, Employment and Workplace Relations; pp. 25-41.

Productivity Commission (2005) Economic Implications of an Ageing Australia. Canberra: Commonwealth of Australia.

Swoboda K (2014) Chronology of major superannuation and retirement income changes in Australia. Canberra: Parliamentary Library, Department of Parliamentary Services. 
Temple J and McDonald P (2017) Population ageing and the labour force: 2000-2015 and 2015-2030. Australasian Journal of Ageing 36(4): 264-270.

Temple J, Rice J, and McDonald P (2017) Ageing and the economic life cycle: The National Transfer Account approach. Australian Journal on Ageing 36(4): 271-278.

Zucchelli E, Jones A, Rice N, and Harris A (2010) The effects of health shocks and labour market exits: evidence from the HILDA Survey. Australian Journal of Labour Economics 13(2): 191-218. 